\title{
Estimativa do vigor de sementes de milho através da avaliação do sistema radicular de plântulas
}

\author{
Estimate of seed vigor of corn through of evaluation of root system of seedlings
}

\begin{abstract}
Patrícia Marluci da Conceição ${ }^{\mathrm{I} *}$ Camilla Atsumi Zanuncio Sediyama ${ }^{\mathrm{I}}$ Rogério Faria Vieira ${ }^{\mathrm{II}}$ João Carlos Cardoso Galvão ${ }^{I}$ Maria Lita Padinha Corrêa ${ }^{I}$ Priscila Soraia da Conceição ${ }^{\mathrm{I}}$
\end{abstract}

\section{RESUMO}

O comprimento da raiz primária das plântulas é usado como teste de vigor de sementes de poáceas, no entanto, além da raiz primária, existe um número variável de raízes seminais, as quais também poderiam ser usadas. Com este trabalho, objetivou-se a avaliação das raízes seminais de plântulas de milho como indicativo do vigor das sementes colhidas em diferentes épocas e submetidas a diferentes métodos de debulha. Para obter lotes de diferentes qualidades, as sementes da variedade de milho UFV-M100 Nativo foram colhidas em diferentes épocas (experimento 1) e submetidas a diferentes métodos de debulha (experimento 2). No experimento 1, as sementes foram colhidas em quatro épocas: quando atingiram o teor de água de 25\% e 10, 20 e 30 dias depois da primeira colheita, em delineamento inteiramente casualizado, com quatro repetições. No experimento 2, as sementes foram colhidas com teor de água de $25 \%$ e submetidas à debulha manual, em debulhador estacionário manual e em debulhador estacionário, no delineamento inteiramente casualizado, com cinco repetições. No experimento 1 , a massa seca das raízes seminais das plântulas diminuiu com o atraso da colheita e correlacionaram-se positivamente com o teste de emergência em leito de areia. No experimento 2, os métodos de debulha não influenciaram as características de raiz e não houve correlação entre elas e a emergência em leito de areia. A massa seca das raízes seminais pode diferenciar o vigor de lotes colhidos em diferentes épocas, mas nenhuma característica de raiz foi eficiente para diferenciar lotes de sementes com variações no dano mecânico.

Palavras-chave: raiz primária, raízes seminais, vigor.

\section{ABSTRACT}

Length of primary root of seedlings is used as seed vigor test of Poaceae. However, besides primary root, there is a variable number of seminal roots, which could have been used. The objective of this work was to evaluate seminal root of corn seedlings as indicative of seed vigor of corn seeds harvested in different seasons and submitted to different threshing methods. To obtain lots with different qualities, UFV-M100 variety corn seeds were harvested in different seasons (experiment 1) and submitted to different threshing methods (experiment 2). In experiment 1, seeds were harvest in four seasons: when they reached water content of 25\%, 10, 20 and 30 days later. In experiment 2, seed were harvested with water content of $25 \%$ and submitted to manual threshing, in manual stationary threshing and in stationary threshing. In experiment 1, mass of dry seminal roots of seedlings was reduced as harvest was delayed and they were positively correlated with emergency test in sand. In experiment 2, methods of threshing did not influence root traits and there was no correlation between them and emergence in sand. It is concluded that mass of dry seminal roots can differentiate vigor of lots harvested in different seasons, but no root trait was efficient to differentiate lots of seeds with mechanical damage variations.

Key words: primary root, seminal roots, vigor.

'Universidade Federal de Viçosa (UFV), 36571-000, Viçosa, MG, Brasil. E-mail: patymarluci@yahoo.com.br. *Autor para correspondência.

"Empresa de Pesquisa Agropecuária de Minas Gerais (EPAMIG), Viçosa, MG, Brasil. 


\section{INTRODUÇÃO}

O teste de germinação é o procedimento oficial para avaliação da capacidade das sementes produzirem plântulas normais em condições ideais, mas nem sempre indica diferenças de desempenho entre lotes de sementes durante o armazenamento ou em campo (CARVALHO \& NAKAGAWA, 2000). Por isso, para análise da qualidade de sementes, há necessidade de complementar as informações fornecidas pelo teste de germinação com testes de vigor, os quais possibilitam selecionar os melhores lotes para comercialização (DIAS et al., 2006). O objetivo básico dos testes de vigor é avaliar ou detectar diferenças significativas na qualidade fisiológica de lotes com germinação semelhante; distinguir, com segurança, lotes de alto dos de baixo vigor; separar ou classificar lotes em diferentes níveis de vigor (MARCOS FILHO, 1999).

Nos testes de vigor baseados no desempenho ou características de plântulas, incluemse os de primeira contagem e velocidade de germinação, comprimento de plântulas ou de suas partes constituintes (raiz primária, hipocótilo e/ou epicótilo), massa seca de plântulas e classificação do vigor (MARCOS FILHO, 2005). Segundo NAKAGAWA (1999), o comprimento médio da plântula ou das suas partes é obtido avaliando-se plântulas normais.

Nas gramíneas, uma maneira de se estimar o vigor das sementes pode ser através das características do sistema radicular, medindo-se o comprimento da raiz primária, no entanto, o sistema radicular embrionário do milho consiste da raiz primária e de um número variável de raízes seminais (HOCHHOLDINGER et al., 2004). Assim, objetivou-se, neste estudo, avaliar as raízes seminais de plântulas de milho como indicativo do vigor das sementes colhidas em diferentes épocas e submetidas a diferentes métodos de debulha.

\section{MATERIAL E MÉTODOS}

Para obtenção de sementes de milho, variedade UFV-M100 Nativo, com diferentes qualidades fisiológicas, as sementes foram colhidas em diferentes épocas (experimento 1) ou submetidas a diferentes tipos de debulha (experimento 2).
Experimento 1

As sementes foram colhidas em quatro épocas: a primeira colheita ocorreu quando as sementes atingiram o teor de água de 25\%; as outras foram realizadas 10, 20 e 30 dias após a primeira colheita, nestas últimas, as sementes estavam com $21 \%$ de umidade. As sementes foram debulhadas manualmente e secas ao sol até atingir o teor de água de 13\%; depois de secas, foram limpas, classificadas, acondicionadas em embalagem de papel multifoliado e armazenadas em câmara fria $\left(20^{\circ} \mathrm{C}\right.$ e $75 \%$ UR) até o momento das avaliações da qualidade fisiológica e do sistema radicular.

Experimento 2

As sementes foram colhidas com teor de água de 25\% e submetidas à debulha manual, em debulhador estacionário manual (rotação de 250rpm) e debulhador estacionário com fonte de alimentação elétrica (rotação de 1500rpm). Após a debulha, as sementes foram secas ao sol até atingir teor de água de $13 \%$, sendo, em seguida, secas, limpas, classificadas, acondicionadas em embalagem de papel multifoliado e armazenadas em câmara fria $\left(20^{\circ} \mathrm{C}\right.$ e $75 \%$ UR) até o momento das avaliações da qualidade fisiológica e sistema radicular.

Para avaliação da qualidade fisiológica, as sementes foram submetidas aos testes de germinação, primeira contagem da germinação, teste de frio sem solo, envelhecimento acelerado, emergência em leito de areia e índice de velocidade de emergência.

No teste de germinação, foram utilizadas três subamostras de 50 sementes por repetição, utilizando como substrato o rolo de papel germitest umedecido com volume de água destilada equivalente a 2,5 vezes a massa do substrato seco. Após a semeadura, os rolos foram mantidos em incubadora BOD a $25^{\circ} \mathrm{C}$, sendo as avaliações realizadas no 7ํ dia após a semeadura, quando foi anotada a porcentagem de plântulas normais (BRASIL, 2009).

A primeira contagem de germinação foi realizada concomitantemente com o teste de germinação, computando-se a porcentagem de plântulas normais no quarto dia após a instalação do teste. 
No teste de frio sem solo, três subamostras de 50 sementes foram distribuídas em papel germitest umedecido com quantidade de água destilada equivalente a 2,5 vezes a sua massa seca; após a semeadura, os rolos foram colocados no interior de sacos plásticos e estes foram mantidos em incubadora BOD regulada a $10^{\circ} \mathrm{C}$ durante sete dias e, sem seguida, os rolos foram transferidos para uma incubadora BOD regulado a $25^{\circ} \mathrm{C}$, onde permaneceram por mais quatro dias. A avaliação da germinação foi realizada de acordo com as recomendações contidas nas Regras para Análise de Sementes (BRASIL, 2009).

No teste de envelhecimento acelerado, três subamostras de 50 sementes foram distribuídas sobre tela de arame no interior de caixas do tipo gerbox com $40 \mathrm{~mL}$ de água destilada, as quais foram acondicionadas em incubadora BOD regulada a $45^{\circ} \mathrm{C}$ por 72 horas. Após esse período, as sementes foram submetidas ao teste de germinação com a contagem de plântulas normais no quarto dia após a instalação do teste.

A emergência em leito de areia foi conduzida em bandejas plásticas, onde três subamostras 50 sementes foram distribuídas em sulcos com $2 \mathrm{~cm}$ de profundidade e mesma distância entre si. O substrato foi umedecido sempre que necessário e a avaliação final das plântulas foi realizada até a estabilização da emergência, que ocorreu 15 dias após a semeadura, cujos resultados foram expressos em porcentagem.

Para determinação do índice de velocidade de emergência, foram realizadas contagens diárias do número de plântulas normais a partir da emergência da primeira, sendo consideradas emergidas as plântulas com plúmulas visíveis e com 2cm de parte aérea e o índice calculado conforme MAGUIRE (1962).

Para avaliação do sistema radicular das plântulas de milho, folhas de papel germitest foram umedecidas com $\mathrm{CaSO}_{4}(0,5 \mathrm{mM})$ e as sementes foram colocadas para germinar dispostas no comprimento do papel com a camada negra voltada para as laterais do papel. Os papéis foram enrolados como rolos de charuto e colocados em béquer de $2 \mathrm{~L}$ com $200 \mathrm{~mL}$ de $\mathrm{CaSO}_{4}(0,5 \mathrm{mM})$. Os béqueres foram cobertos com plástico perfurado e colocados em incubadora BOD, a $28^{\circ} \mathrm{C}$. Quatro dias após a montagem do teste, em quatro plântulas normais de cada repetição, foram avaliados: o número de raízes seminais, o comprimento da raiz primária e raízes seminais e a massa da raiz primária e raízes seminais secas.

O experimento 1 foi instalado no delineamento inteiramente casualizado com quatro repetições e os dados foram submetidos à análise de variância e de regressão, cujos modelos de regressão escolhidos foram baseados na significância dos coeficientes com o teste t, adotando-se o nível de 5\% de probabilidade no coeficiente de determinação $\left(\mathrm{R}^{2}\right) \mathrm{e}$ no fenômeno biológico a ser descrito. Para fins de análise estatística, os dados obtidos em porcentagem foram previamente transformados em arco seno v\%/ 100 , para atender a distribuição normal; nos gráficos, são apresentados os dados transformados.

O experimento 2 foi instalado no delineamento inteiramente casualizado com cinco repetições, sendo os dados submetidos à análise de variância e as médias comparadas pelo teste de Tukey, a 5\% de probabilidade, quando o teste $\mathrm{F}$ foi significativo. Para fins de análise estatística, os dados obtidos no teste de emergência em leito de areia foram previamente transformados em arco seno v\%/100, para atender a distribuição normal e na tabela são apresentados os dados transformados.

Nos dois experimentos, foram calculados os coeficientes de correlação de Pearson (r) entre o resultado do teste de emergência em leito de areia e os demais testes.

\section{RESULTADOS E DISCUSSÃO}

As épocas de colheita não influenciaram significativamente os resultados dos testes de primeira contagem da germinação, frio sem solo, número de raízes seminais, comprimento e massa da raiz primária seca. Com o atraso da colheita das sementes, houve redução no número de plântulas normais nos testes de germinação, envelhecimento acelerado, na porcentagem e velocidade de emergência das plântulas (Figura 1). Segundo SANTOS (1993), os danos à qualidade

Ciência Rural, v.42, n.4, abr, 2012. 


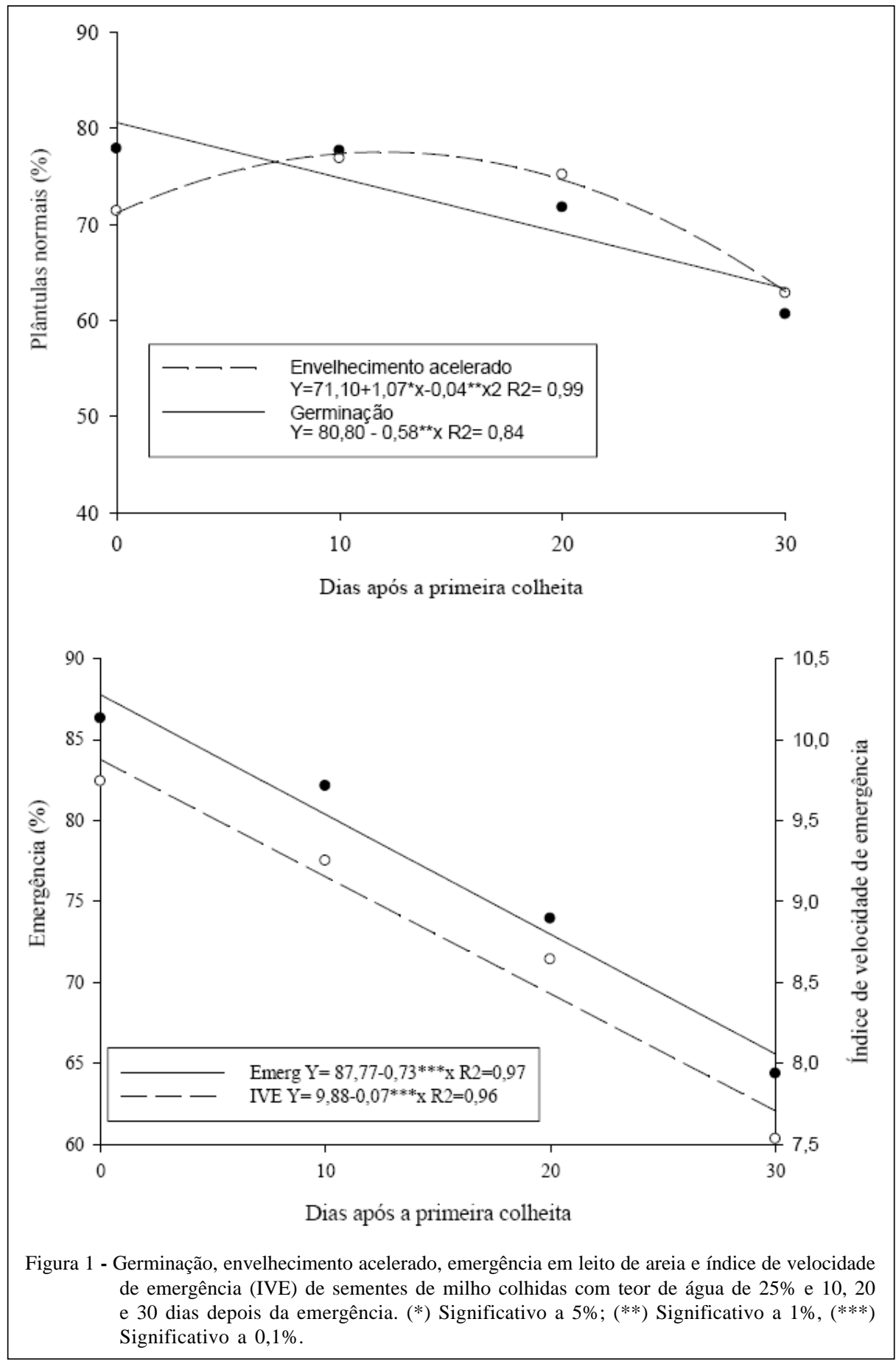

fisiológica das sementes, com o atraso da colheita, variam de região para região, dependendo das condições climáticas, como umidade do ar, temperatura e insolação, sendo que fatores como insetos (gorgulhos e traças), pássaros, chuvas e ventos contribuem para aumentar as perdas pelo atraso na colheita.
Em relação às características do sistema radicular, o atraso da colheita diminuiu o comprimento e massa das raízes seminais (Figura 2), enquanto não houve influência do atraso da colheita nas avaliações da raiz primária. Possivelmente, após os quatro dias do início do processo de germinação das sementes, 


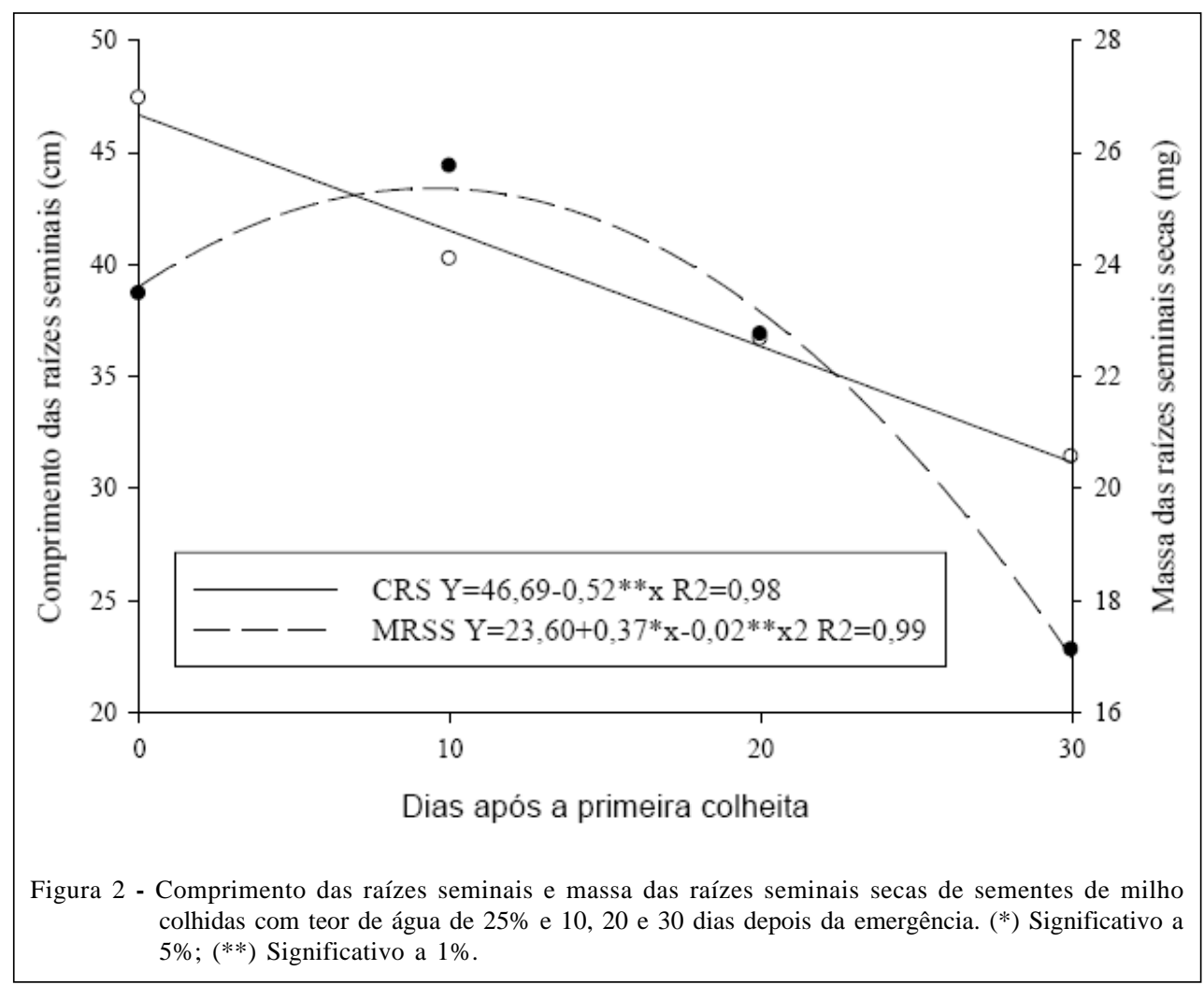

momento em que as características do sistema radicular foram analisadas, o crescimento da raiz primária já estava mais lento e, com isso, não houve diferença no seu crescimento. Segundo VIEIRA \& CARVALHO (1994), as partes das plantas observadas no teste de vigor devem estar em pleno crescimento, pois há tendência da estabilização do crescimento. No entanto, as raízes seminais, que se desenvolvem após a raiz primária, estão em pleno crescimento, o que permite a observação de diferenças entre as suas características provenientes de sementes de diferentes qualidades. Assim, as características das raízes seminais podem ser mais utilizadas como indicativo do vigor, comparado à raiz primária.

As épocas de colheita não influenciaram significativamente no número de raízes seminais, com uma média de cinco raízes seminais. Segundo HOCHHOLDINGER et al. (2004), o número de raízes seminais por plântula é fortemente influenciável pelo genótipo, no entanto não foi influenciado pelo vigor.

Um teste de vigor para ser considerado eficiente deve representar o que acontece com a emergência das plântulas originadas das sementes avaliadas (MARCOS FILHO, 1999). O teste de germinação, apesar de não ser um teste de vigor e avaliar a capacidade das sementes produzirem plântulas normais em condições ideais, mostrou correlação positiva e significativa com o teste de emergência. Os testes de envelhecimento acelerado e índice de velocidade de emergência também apresentaram correlação positiva e significativa com o teste de emergência em leito de areia; nas avaliações do sistema radicular, somente a massa das raízes seminais secas mostrou correlação significativa com o teste de emergência (Tabela 1).

Não houve efeito significativo dos métodos de debulha nas avaliações das características do

Ciência Rural, v.42, n.4, abr, 2012. 
Tabela 1 - Coeficiente de correlação de Pearson (r) entre os resultados do teste de emergência de plântulas em leito de areia e os testes de germinação (GERM), envelhecimento acelerado (EA), índice de velocidade de emergência (IVE), comprimento das raízes seminais (CRS) e massa das raízes seminais secas (MRSS) de sementes de milho colhidas em quatro épocas.

\begin{tabular}{cccccc}
\hline Testes & GERM & EA & IVE & CRS & MRSS \\
\hline$r$ & $0,90^{* * *}$ & $0,67^{* *}$ & $0,97^{* * *}$ & $0,55^{\text {ns }}$ & $0,64^{*}$ \\
\hline
\end{tabular}

(*)Significativo a 5\%; (**)Significativo a 1\%; (***)Significativo a 0,1\%, (ns) Não significativo, a 5\% de probabilidade.

sistema radicular das plântulas. A qualidade fisiológica das sementes submetidas ao debulhador estacionário manual foi menor (Tabela 2). O debulhador estacionário manual é pouco eficiente na debulha das sementes e muitas espigas tiveram que passar duas vezes pelo debulhador, o que possivelmente aumentou os danos às sementes. O teor de água de $25 \%$ dificultou a debulha no debulhador estacionário manual (rotação de 250rpm) comparado ao debulhador estacionário com fonte de alimentação elétrica (rotação de 1500rpm), pois, quanto mais úmidas as sementes, maior a dificuldade de debulhá-las, exigindo maior rotação do cilindro debulhador.

Os efeitos dos danos mecânicos durante a debulha não foram observados no sistema radicular, porque nem todas as sementes recebem as injúrias durante a debulha. Nas avaliações do sistema radicular, somente as plântulas normais foram avaliadas, e estas, possivelmente, originaram-se de sementes que não sofreram danos mecânicos. Logo, as características de raiz foram ineficazes para diferenciar lotes com variações de danos mecânicos.

Os testes de germinação, primeira contagem da germinação, envelhecimento acelerado e índice de velocidade de emergência tiveram correlação positiva e significativa com o teste de emergência em leito de areia (Tabela 3).

Os resultados deste trabalho sugerem que a avaliação do sistema radicular não é eficiente para avaliar os efeitos de danos mecânicos ocorridos durante a colheita, beneficiamento, armazenamento e transporte das sementes.

\section{CONCLUSÃO}

A massa das raízes seminais secas das plântulas diferencia o vigor de lotes de sementes submetidos a diferentes épocas de colheita. As características das raízes seminais não diferenciam os lotes de sementes de milho submetidas a danos mecânicos.

Tabela 2 - Teste de germinação (GERM), primeira contagem da germinação (PC), teste de frio sem solo (TF), envelhecimento acelerado (EA), emergência de plântulas em leito de areia (EMERG) e índice de velocidade de emergência (IVE) em sementes de milho submetidas a três métodos de debulha: manual (1), com debulhador estacionário manual (2) e debulhador estacionário (3).

\begin{tabular}{|c|c|c|c|c|c|c|}
\hline Tratamentos & GERM (\%) & PC (\%) & $\mathrm{TF}(\%)$ & EA (\%) & EMERG (\%) & IVE \\
\hline 1 & $97 \mathrm{~A}$ & $94 \mathrm{~A}$ & $93 \mathrm{~A}$ & $72 \mathrm{~A}$ & $77 \mathrm{~A}$ & $9,15 \mathrm{~A}$ \\
\hline 2 & $55 \mathrm{~B}$ & $45 \mathrm{~B}$ & $42 \mathrm{~B}$ & $33 \mathrm{~B}$ & $47 \mathrm{~B}$ & $5,04 \mathrm{~B}$ \\
\hline 3 & $88 \mathrm{~A}$ & $83 \mathrm{~A}$ & $79 \mathrm{~A}$ & $61 \mathrm{~A}$ & $69 \mathrm{~A}$ & $8,43 \mathrm{~A}$ \\
\hline $\mathrm{CV}(\%)$ & 10,67 & 15,3 & 13,98 & 15,5 & 7,37 & 9,53 \\
\hline
\end{tabular}

Médias seguidas de mesma letra maiúscula nas colunas não diferem entre si pelo teste Tukey, a 5\% de probabilidade. 
Tabela 3 - Coeficiente de correlação de Pearson (r) entre os resultados do teste de emergência de plântulas em leito de areia e os testes de germinação (GERM), primeira contagem de germinação (PC), envelhecimento acelerado (EA) e índice de velocidade de emergência (IVE) das sementes submetidas a diferentes métodos de debulha.

\begin{tabular}{lccccc}
\hline Testes & GERM (\%) & PC (\%) & TF (\%) & EA (\%) \\
\hline $\mathrm{R}$ & $0,96^{* * *}$ & $0,96^{* * *}$ & $0,95^{* * *}$ & $0,95^{* * *}$ & $0,98^{* * *}$ \\
\hline
\end{tabular}

$(* * *)$ Significativo a $0,1 \%$ de probabilidade.

\section{AGRADECIMENTOS}

Ao Conselho Nacional de Desenvolvimento Científico e Tecnológico (CNPq) e à Coordenação de Aperfeiçoamento de Pessoal de Nível Superior (Capes).

\section{REFERÊNCIAS}

BRASIL. Ministério da Agricultura, Pecuária e Abastecimento. Regras para análise de sementes. Secretaria de Defesa Agropecuária. Brasília: SNDA/DNDV/CLAV, 2009. 395p.

CARVALHO, N.M.; NAKAGAWA, J. Sementes: ciência, tecnologia e produção. 4.ed. Jaboticabal: FUNEP, 2000. 524p.

DIAS, D.C.F.S. et al. Teste de condutividade elétrica para avaliação do vigor de sementes de cebola. Revista Brasileira de Sementes, v.28, n.1, p.154-162, 2006. Disponível em: $<\mathrm{h} \mathrm{t}$ t p : / / w w w. s c i e l o . b r / scielo.php?script=sci_arttext\&pid=S010131222006000100022\&lng=pt\&nrm=iso\&tlng=pt>. Acesso em: 04 jan. 2012. doi: 10.1590/S0101-31222006000100022.

HOCHHOLDINGER, F. et al. From weeds to crops: genetic analysis of root development in cereals. Trends in Plant Science, v.9, n.1, p.42-48, 2004. Disponível em: <http:// www.sciencedirect.com.ez31.periodicos.capes.gov.br/science/
article/pii/S1360138503002978>. Acesso em: 04 jan. 2012. doi:10.1016/j.tplants.2003.11.003.

MAGUIRE, J.D. Speed of germination-aid in selection and evaluation for seedling emergence and vigor. Crop Science, v.2, n.1, p.176-177, 1962. Disponível em: <https:// www.crops.org/publications/cs/pdfs/2/2/CS0020020176>. Acesso em: 31 jan. 2012 doi:10.2135/ cropsci1962.0011183X000200020033x.

MARCOS FILHO, J. Fisiologia de sementes de plantas cultivadas. Piracicaba, FEALQ, 2005. 495p.

MARCOS FILHO, J. Testes de vigor: importância e utilização. In: KRZYZANOWSKI, F.C. et al. Vigor de sementes: conceitos e testes. Londrina: ABRATES, 1999. p.1.1-1.21.

NAKAGAWA, J. Testes de vigor baseados no desempenho das plântulas. In: KRZYZANOSKI, F.C. et al. Vigor de sementes: conceitos e testes. Londrina: ABRATES, 1999. p.2.1-2.24.

SANTOS, J.P. Recomendações para o controle de pragas de grãos e de sementes armazenadas. In: BÜLL, L.T.; CANTARELlA, H. (Ed.). Cultura do milho: fatores que afetam a produtividade. Piracicaba: Potafos, 1993. p.197236.

VIEIRA, R.D.; CARVALHO, N.M. Testes de vigor em sementes. Jaboticabal: FUNEP, 1994. 164p. 